
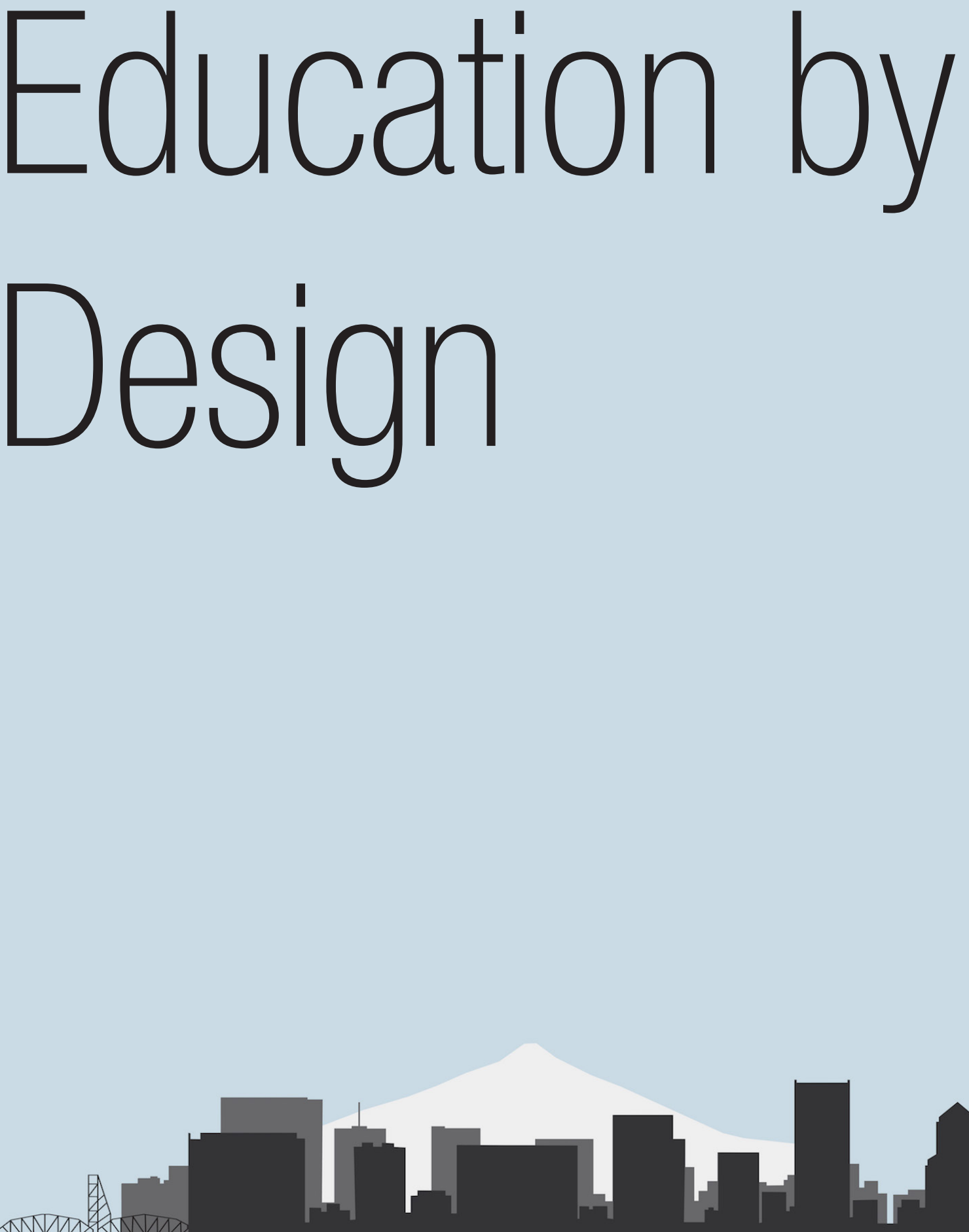

2019 Reynolds Symposium: Education by Design October 18-20, 2019 


\section{Organizing Committee:}

[co-organizers]

Professor Alison Kwok, Ph.D, FAIA, University of Oregon

Emeritus Professor John Reynolds, FAIA, University of Oregon

\section{[Symposium coordinator]}

Isabel Rivera, Ph.D., University of Oregon

Professor Walter Grondzik, P.E., Ball State University

Professor Bruce Haglund, AIA Assoc., University of Idaho

Assistant Professor Emily McGlohn, AIA, Auburn University

Associate Professor Ulrike Passe, lowa State University

Assistant Professor Siobhan Rockcastle, Ph.D., University of Oregon

Sharon Refvem, FAIA, LEED Fellow, Senior Associate and Director, Sustainability Resource Group, Hawley Peterson Snyder 


\title{
From Problem to Net Positive: The transformation of existing, inefficient building stock
}

\author{
Malini Srivastava, AIA \\ Assistant Professor \& Director (MS-RP) \\ University of Minnesota \\ Minneapolis, Minnesota \\ malini@umn.edu
}

\begin{abstract}
The Net Positive studio is a 7-week studio in the penultimate year of a professional M. Arch. program at the University of Minnesota. This studio focuses on developing, assessing, documenting, and representing interaction between architectural form and environmental factors, using energy modeling tools and incorporating frequent quantitative feedback.

In the context of existing-building inefficiency as a major contributor to carbon emissions and climate change, students were assigned an existing building, and were required to demonstrate that passive and active modifications of the building and its envelope could lead to an $80 \%$ reduction of its baseline energy use. Within this context, students were asked to (a) selectively modify or replace existing envelope conditions to create a responsive deep-boundary; (b) establish a dialogue between energy-modeling tools and conceptual development; (c) incorporate a Net-Positive contribution beyond energy production; and (d) understand variables that develop concinnity between form, occupancy and function, and environmental factors.
\end{abstract}

These goals were established within a cooperative pedagogy, Shifting Allegiances, organized to promote cooperative collaboration and shared authorship of projects in graduate-level studios. This is achieved by collectivizing the ownership of topical subject areas, to which students variously direct their effort over the course of the studio.

The paper discusses the studio's cooperative structures, the process of establishing an ongoing dialogic between quantitative data and conceptual development, the role of energy modeling within the design process, and the emerging definition of passive and active envelope systems. The paper concludes with a discussion of the studio's discussion-based, student-led final review.

\subsection{THE NET-POSITIVE DESIGN STUDIO}

The Net-Positive Design Studio is offered in the penultimate year of a 3-year professional Master of Architecture degree program at the School of Architecture, College of Design, University of Minnesota. The Spring semester of the second year in the program is divided into two approximately 7-week long modules. The Net-Positive Design Studio, in the first of the two modules, focuses on the integration of architectural design, environmental technology, and high-performance regenerative practice. Although the three or four sections have an overall alignment in schedule for all-studio lectures, consultant workshops, and energy modeling training, each section follows their own projects and emphasis. The brief for all sections reads, "in the Net Positive studio, architectural design integrates design excellence, beauty, and theories of architecture with the achievement of performance standards. Historically, these standards have been checklist based and focused on the built environment as being less bad rather than having positive effects. The goal of the studio is to evolve high performance design strategies, apply processes and techniques to improve performance, and redefine architectural beauty from a socioecological perspective." Furthermore, all sections of the Net-Positive studio share the following key topics: first, utilizing design processes and methods to explore the form-giving potential of ecological and performance-driven design; second, measuring ecological sustainability with assessment tools, guidelines, 
metrics and frameworks; and third, developing, assessing, documenting, and representing the interaction of architectural form and environmental factors and systems.

\subsection{ACTING ON EXISTING BUILDINGS}

This paper discusses the premise and work of the Spring 2019 Net-Positive studio section led by this paper's author. This section of studio augmented the shared objectives with the following key components:

1. Acting on existing buildings to make them net-positive contributors to the environment and society.

2. Absenting authorship and focusing on shared, fluid, and cooperative structures to accelerate investigative potential of the studio as a whole and focus on peer-teaching.

3. Defining Net-Positive in response to passive, active, responsive/adaptive, and resilient building skins or interfaces.

4. Proposing larger-scale agency for buildings and architects to provide a Net-Positive impact on the environment through the project being designed but beyond the confines of the project.

As climate change accelerates, the need for training architects to respond to these changes at a mass scale becomes increasingly urgent and imperative. Elefante (2018) writes that "[e]xisting buildings are a resource for tackling climate change ... Retrofitting existing buildings to meet high-performance standards is the most effective strategy for reducing near- and mid-term carbon emissions, the most important step in limiting climate disruption." Existing buildings are problematic in that they are large energy consumers and carbon emitters while simultaneously being repositories of embodied carbon. Elefante projects that over the next 30 years more than twice as many buildings will be renovated than newly constructed.

The Net-Positive studio section led by this paper's author provided two starting conditions. First, based on the premise that these wicked problems require cognitive diversity in order to address their complexities, the studio positioned the creating of fluid cooperative structures as part of the studio process. Second, it positioned the skins of existing buildings, envelope, and surfaces as the interface between controlled and uncontrolled environments that have the potential to achieve net-positive and resiliency goals.

\subsection{BUILDING INTERFACES}

The studio section asked students to redesign, transform, and expand the interface of an existing urban ice-cream manufacturing and retail facility to achieve two goals in succession. First, students were asked to selectively modify or completely replace the building's existing boundary condition, in order to create a passive, high-performing, deep boundary condition reducing the building's estimated current energy use by $70 \%$. Then, students were asked to newly imagine and design an active or adaptive layer for the existing building - i. e., a cloak or shield - creating a modulated exterior environment as a responsive, resilient, and adaptive building interface for a fast-changing climate. Interfaces were simultaneously positioned as the separator and connector of environments within and without, and in this capacity shaped not only human experience but also their own surroundings. Students were provided with reference materials and key concepts to support their research and design work throughout the course of the studio. For the high-performance passive response, Dr Joseph Lstiburek's Perfect Wall system, especially as it relates to Passive House performance, required students to develop an understanding of various building envelope layers and their properties (Lstiburek 2007). Students developed their strategies through wall sections, in which they detailed, examined, compared, and critiqued the layerings of high-performance envelopes. Simultaneously, energy modeling positioned the building envelope as one of the variables in overall building performance goals.

For the research and design of the adaptive layer or cloak, students were provided with reference materials and a taxonomy as defined by Loonen et al. (2010, 2013), supporting the design of climate 
adaptive building shells. For Loonen et al., "a climate adaptive building shell has the ability to repeatedly and reversibly change some of its functions, features or behavior over time in response to changing performance requirements and variable boundary conditions and does this with the aim of improving overall building performance.” Loonen's taxonomy included thermal, optical, airflow and electrical responses in the adaptive skin.

Students were allowed to propose (a) changes in massing that transformed the existing building's orientation, volume-to-surface-area ratio, and opacity-to-transparency ratio for greater passive efficiency; (b) changes or modifications in program and occupancy for net-positive impact, especially in the realm of socio-economic benefits that supported equity and resiliency; and (c) the addition of active or passive means of energy production.

\section{4.o CREATING CONFLATIONS AND COOPERATIVE STRUCTURES}

While the instructor designed the overall structure of the studio including schedules, goals, and evaluation criteria, the day-to-day and week-to-week studio structures were developed in partnership by the students and instructor through large- and small-group discussions. With a couple of exceptions, the studio day started and ended with a large group meeting where instructor and students participated. Key issues of discussion were problems encountered, thematic concepts that were being observed and articulated, work plan and announcements. Focus is on (a) observing, reading, and articulating the thematic concepts emerging in the studio, and combining work generated by various people to strengthen emerging themes; (b) what was next, in other words what was being made, researched, or tested in order to advance concepts and by whom (Srivastsava, Christenson 2018 and Srivastava, Barton, Christenson 2019)

Between the all-studio discussions at the beginning and end of the studio period, the instructor and students decided upon the day's activities and related structures. The most common structures were small group discussions and documentations in various permutations and combinations with or without the instructor. Sometimes the studio day was spent as a workday by the students working in various permutations. Ideally the evolving cooperative structures were based on need and thematic and interest overlaps.

At pre-determined points during the semester, during the studio period, the studio would gather together for a substantive amount of time to bring all the work together, with the instructor acting as an observer rather than as an active participant. For example, early in the Net-Positive studio, each student responded to the following variables by producing at least four artifacts (Figure 1 left, Figure 2), each of which proposed changes to the existing building's massing to achieve better performance:

(a) better energy-use performance in terms of volume-to-surface-area ratio and/or opacity-totransparency ratio;

(b) better energy-use performance in terms of orientation and/or envelope section;

(c) active (energy-powered), and/or adaptive (able to change in response to changing environmental conditions), and/or an energy-production strategy;

(d) one other criterion in addition to energy-efficiency (such as water, biophilia, waste, etc.) so that the building can make a net-positive contribution to the surrounding built environment and living community (Mang and Reed 2015).

Through discussion, various works were repeatedly moved around the table for thematic overlap (Figure 1 middle \& right, Figure 3). Various works were grouped together based on all-studio agreed upon and evolving definitions of thematic adjacencies and overlaps (Figure 3, Figure 4). Depending upon interest and need for skill development, students took ownership of groups of artifacts to develop (Figure 5). 

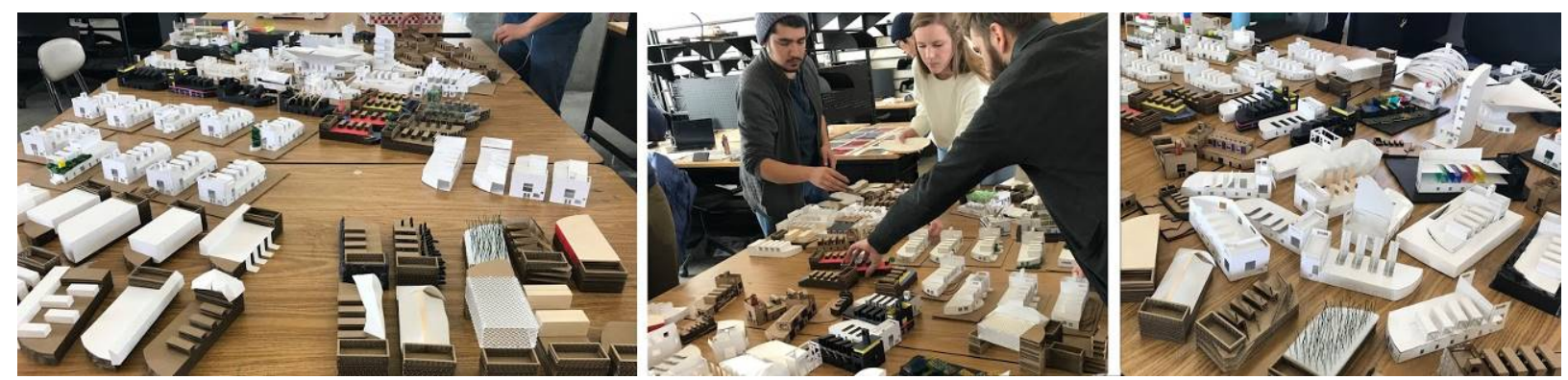

Figure 1. Fluid conflations and evolving thematic and student groupings in the Net Positive studio, existing building section

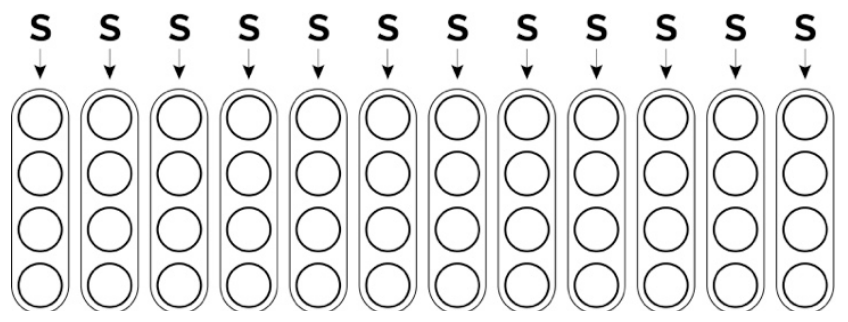

Figure 2. SETTING THE TABLE: Each student (S) contributes multiple artifacts to the studio for discussion (circles circles represent artifacts)
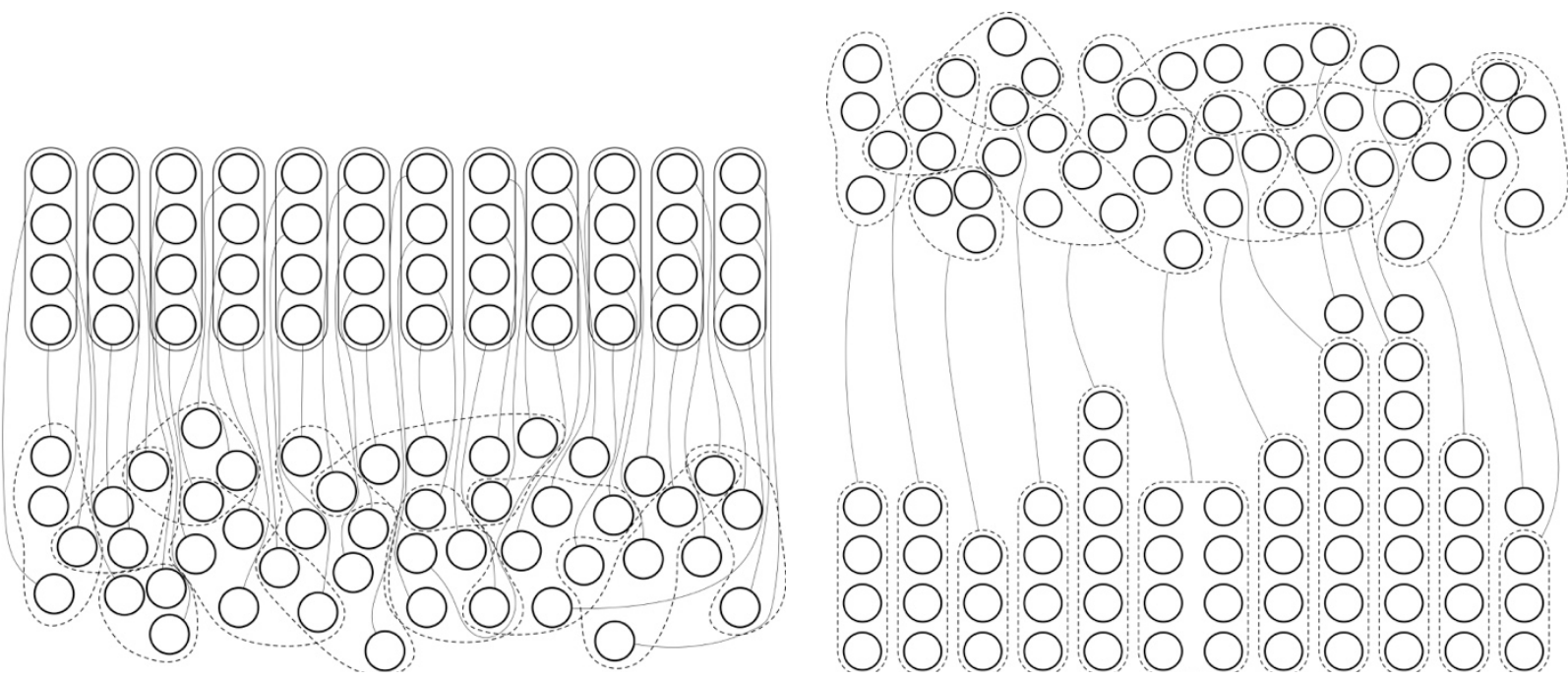

Figure 3. CONFLATION (left): Through discussion, various works are repeatedly moved around the table for thematic overlap; GROUPINGS OF ARTIFACTS (right): Various works are grouped together based on all-studio agreed upon and evolving definitions of thematic adjacencies and overlaps (circles represent artifacts; dashed lines are thematic groupings) 


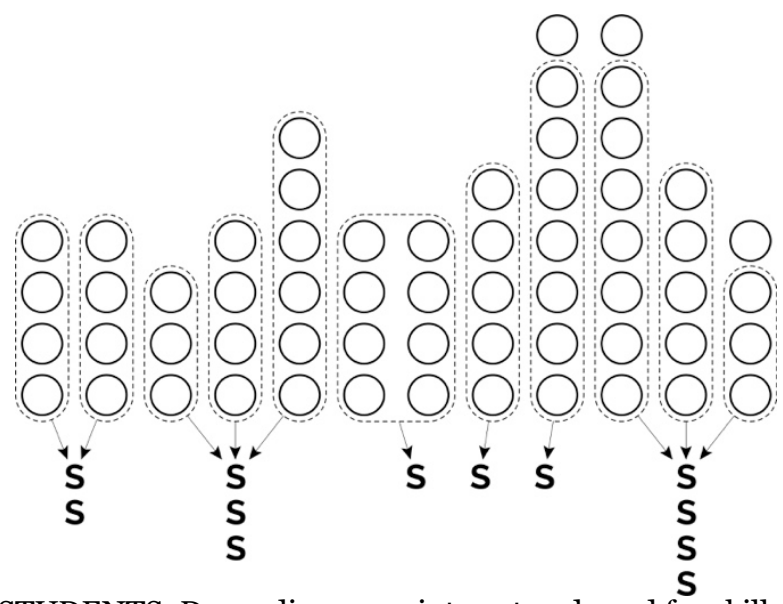

Figure 4. GROUPINGS OF STUDENTS: Depending upon interest and need for skill development, students take on groups of artifacts to develop; student groups and individual work expectations are outlined as the last step in this discussion (circles represent artifacts, dashed lines are thematic groupings)

\section{O EXAMPLES OF STUDENT-DEFINED COOPERATIVE STRUCTURES}

Various thematic groupings of work and people that evolved ranged from 3-person groups to 1person efforts. Two examples are described in detail here.

First, a three-person group formed to share research and testing tasks (Figure 5). Together, they created one group design and three individual design solutions. All three shared an interest in double-skin wall sections and in making a net-positive contribution by converting waste (generated during the ice cream manufacturing, storage, retailing, packaging, and transporting processes) to compost, which is in turn converted to energy production.
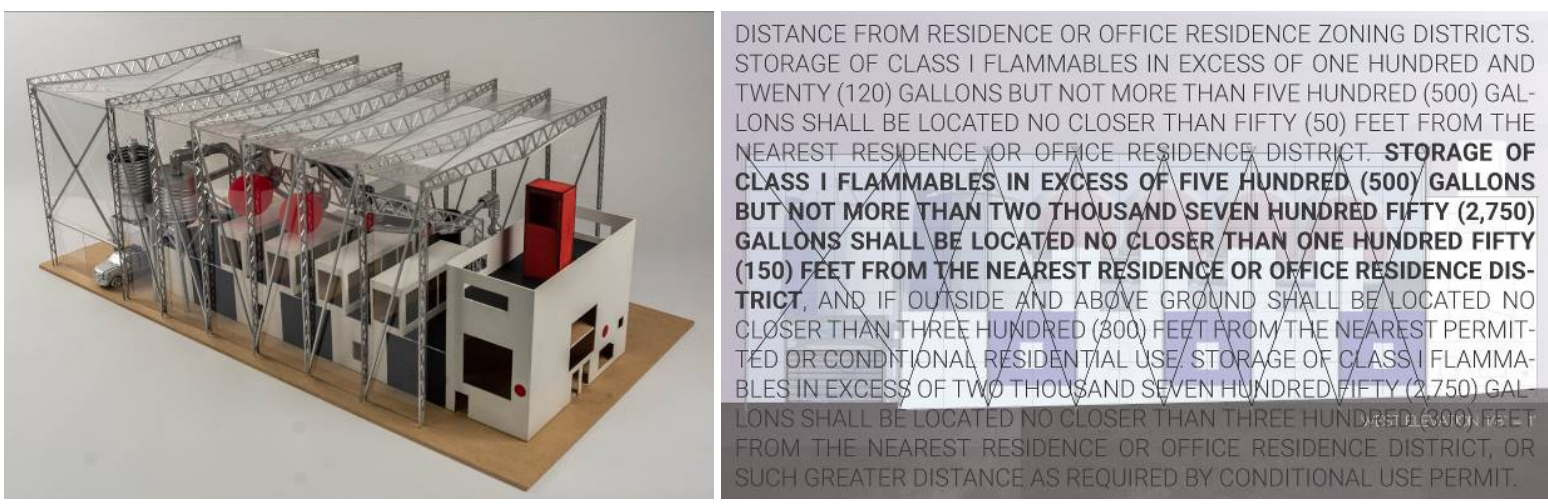

Figure 5. Ice-Cream compost waste to energy (artifacts by Ashleigh Grizzell, Garrett Hulse, Adam Rosenthal) 
Second, another student worked individually (Figure 6), researching and creating façade layers that acted as air-cleaning filters for the neighborhood, and dynamic wall systems that created a more expansive and community-oriented use of the ice-cream retail space. Other students in the group organized in different ways. A second three-person group formed to divide research and energy-modeling tasks. They created a common massing design with three individual design solutions for passive and adaptive interface solutions. Their common interests were equity and job creation in the future green economy, use of algae for energy production in urban environments, and creating slow manually-powered responsive skin structures. Yet another three-person group, more loosely organized than the other groups, shared some background research and energy modeling evaluation techniques based on a common interest in biophilia. All three members of this group shared research tasks and produced individual design solutions, form transformations, and passive and responsive building interfaces. Finally, two students had a small overlap; they worked and championed independent design solutions and had very different workflows. They shared an interest in Grasshopper, Ladybug, and other software to evaluate existing conditions and iterate design ideas while simultaneously evaluating their performance. They became peer-teachers for each other. They both also shared an interest in minimal external change in the existing building, creating most of their interventions and layering on the interior of the current envelope.

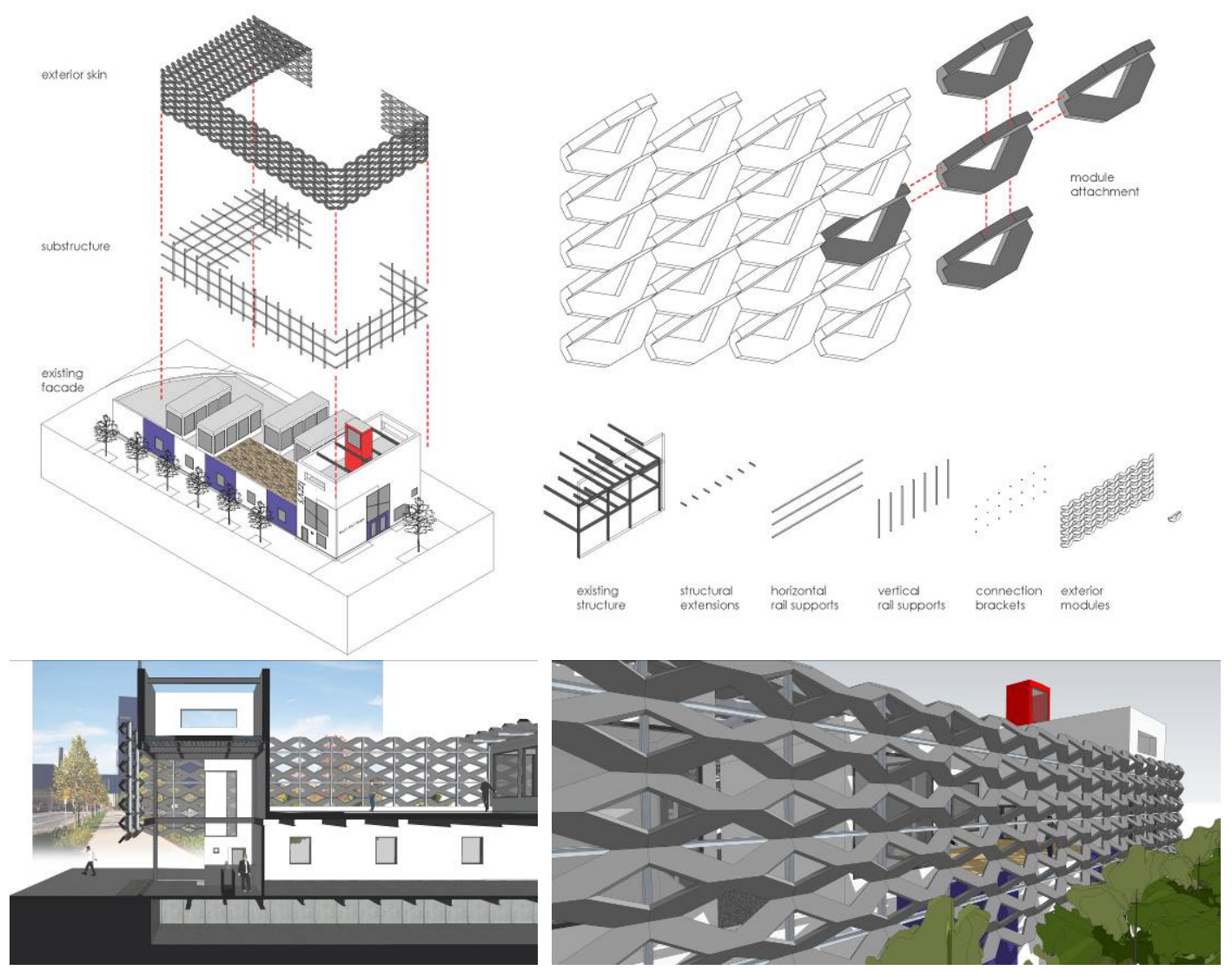

Figure 6. Building as pollutant filter (Artifacts by Alejandro Loza)

\section{6.o DISCUSSION OF IMPACT}

The impacts of approaching the complexity of transforming an existing building to achieve Net-Positive results in a short period of time through the Shifting Allegiances pedagogy were observed in a few different ways. One of the most important impacts was the establishment of collaborative structures to examine design concepts, performance variables, and related results as an all-studio comparative exercise. Three observed outcomes of this phenomenon are discussed in the following sections. 


\subsection{AN ONGOING DIALOG BETWEEN CONCEPTUAL DEVELOPMENT AND DATA}

The Shifting Allegiances approach was essential in addressing the complexity inherent in the Net-Positive studio, particularly in the cycle between energy modeling and design. As part of the evidence-driven process, the students were required to individually demonstrate mastery of the energy-modeling software. To do this, two Friday studios were dedicated to energy-modeling workshops followed by an energymodeling related weekend charrette and a Monday review of the findings with the workshop instructors, Chris Wingate and Pat Smith). The first workshop (in the second week) included fundamental passive design variables such as orientation, massing, opacity and transparency ratios, and surface-area-tovolume ratios. The second workshop (in the fourth week) introduced mechanical, electrical, and lighting systems. It also introduced building envelope performance based on varying R-values. After the first workshop, design processes were expected to follow a cyclical, iterative process of making and testing. Any drawings or models made to develop design ideas alternated with energy modeling for performance. Thus, design and performance were intrinsically tied in a cyclical process each informing the other (Figure 7).

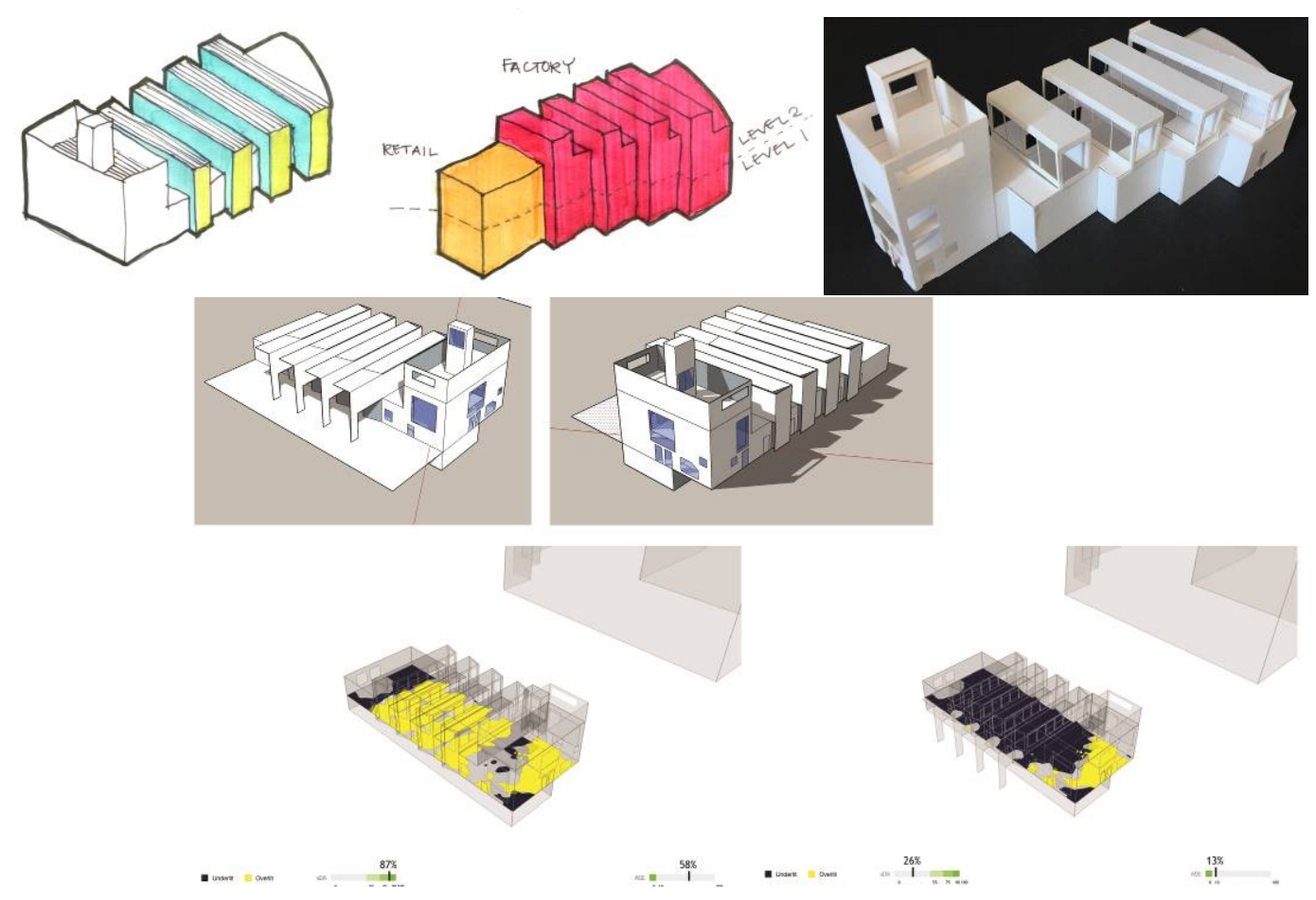

Figure 7. Cyclical process between ideation and testing (MacKenzie Kusler)

Since they were dealing with an existing building with a very particular and high energy use (associated with the refrigeration involved in ice-cream production), and because they were regularly engaged in each other's works through small-group and large-group discussions and work conflations, the students began to notice that the energy modeling software they were using was not producing consistent results. Students experimenting with the same or similar design concepts were encountering varying results in Energy Use Intensity (EUI). In order to investigate this further, they began a systematic group review of the software. The whole studio decided to use the same baseline model of the existing building, developed by a volunteer student, and they all tested the same series of design iterations. They all recorded their results in a shared spreadsheet. It was quickly evident that they all were getting different results. They went through this cycle a few times, checking settings in the energy modeler to make sure everyone was starting with a consistent baseline. After systems, occupancy patterns, and envelope modeling had been 
introduced in Week 4, the students requested existing building occupancy patterns, systems information, and utility bills from the current owner. They were then able to individually model the same parameters in the energy modeler, producing closer results for the predicted energy use (Table 1). This became a cycle of consistent and systematic testing where all the students worked cooperatively to develop not just familiarity with the modeling process but a deep understanding of the results that the software produced. Helping each other by testing multiple iterations together demonstrated their understanding of energy modeling and its potential drawbacks. They quickly started to realize that concinnity between variables such as form, occupancy, building envelope layers, transparency and opacity ratios, massing, orientation, function, and environmental factors lead to determining performance but at the same time, they were able to conclude that the software is not flawless.

Table 1. Comparisons of student energy modeling result, using the same baseline model and design iteration after several attempts to align results by examining several design variables

\begin{tabular}{|c|c|c|c|c|c|}
\hline $\begin{array}{c}\text { Student } \\
\text { code }\end{array}$ & SF & $\begin{array}{c}\text { EUI Plug } \\
\text { In }\end{array}$ & $\begin{array}{c}\text { EUI Web } \\
\text { App }\end{array}$ & $\begin{array}{c}\text { kWh Web } \\
\text { App }\end{array}$ & $\begin{array}{c}\text { Sketch Up } \\
\text { Version }\end{array}$ \\
\hline Student 1 & 8429 & 51 & 51 & 124,907 & Make - 2017 \\
\hline Student 2 & 8429 & 51 & 49 & 119,418 & Make - 2017 \\
\hline Student 3 & 8429 & 51 & 51 & 124,907 & Make - 2017 \\
\hline Student 4 & 8429 & 51 & 49 & 119,418 & Make - 2015 \\
\hline Student 5 & 8429 & 51 & 49 & 119,418 & Make - 2017 \\
\hline Student 6 & 8429 & 51 & 51 & 124,541 & Make - 2017 \\
\hline Student 8 & 8357 & 51 & 51 & 124,907 & Pro-2018 \\
\hline Student 9 & 8429 & 51 & 49 & 119,418 & Make - 2017 \\
\hline Student 10 & 8429 & 51 & 48 & 118,170 & Make - 2017 \\
\hline
\end{tabular}

If they had worked in the traditional studio format where each person had their own model, and no structure or basis for comparison, or peer-learning support, they would not have deepened their understanding of energy modeling as this group did. In the end they submitted all their comparative result spreadsheets to the local representative of the energy modeling software to get an expert's explanation of the anomalies and variations they had discovered.

\subsection{REVIEW FORMATS}

As the end of the semester neared, the instructor and students discussed continuing the discussion-based format of the studio to the final review. The cooperative structures had created investment in the individual and collective work of the studio to various degrees and heightened the opportunities for peer learning. In the penultimate week of the studio, the students gathered with an external reviewer and practiced a discussion-based review, where the students presented the work in quick succession, outlining an issue or question they wanted the studio and external reviewer to respond to. After these quick presentations, the entire studio discussed all the work, pointing out thematic similarities and overlaps in the work. They spontaneously diagrammed the work of the studio on a three-dimensional spectrum where $x, y$, and $z$ axes represented various common themes in the projects (Figure 8).

Based on this experience, the studio created a shared Google spreadsheet (Table 2) outlining what they had learned from the practice review, and several students modified or changed the discussion question or issue they wanted to tackle. Two examples of this are shown in Table 2.

Learning from the practice review, the students also proposed a new format where all the work of the studio was simultaneously displayed and available for reference. Half of the studio presented work in quick succession grouped by thematic overlap, followed by a group discussion where students and 
external reviewers arranged themselves in a circle (Figure 9). Both the penultimate and final reviews were moderated by student volunteers, Megan Lundquist and Robert Pekrul. During the final review, the volunteer moderator also added two rules to the group discussion at the halfway point, in order to ensure that the discussion stayed related to and referenced the studio's work while also forwarding larger issues of climate change provoked by the work. The discussion-based practice review and final review placed the students in a leadership role, empowering them to design the review structure based on the content.
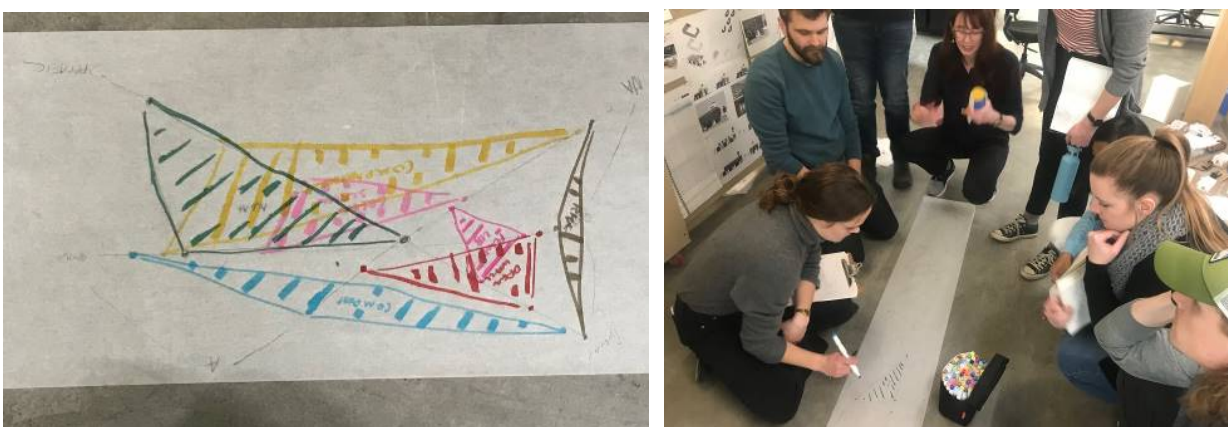

Figure 8: Practice review and spontaneous diagramming to place all student work on a 3-dimensional spectrum of common variables

Table 2. Studio-generated spreadsheet outlining practice and final review questions in order to organize a studentled discussion-based review

\begin{tabular}{|c|c|c|c|}
\hline & $\begin{array}{l}\text { Practice review } \\
\text { questions }\end{array}$ & Practice review take-away & $\begin{array}{l}\text { New final review } \\
\text { questions }\end{array}$ \\
\hline Student 1 & $\begin{array}{l}\text { How can a focus on } \\
\text { labor and equitable } \\
\text { human experience } \\
\text { contribute to a Net } \\
\text { Positive strategy? }\end{array}$ & $\begin{array}{l}\text { I was interested in how the } \\
\text { questions/discussion generated new questions } \\
\text { that have implications on our work. For } \\
\text { instance, the question of a 30-year building vs a } \\
\text { 200-year building was raised. I'm still thinking } \\
\text { about that question's impact - the materials that } \\
\text { we have chosen for our passive and active } \\
\text { strategies are largely biodegradable. These sorts } \\
\text { of complicated, multi-variable questions that } \\
\text { act across multiple time scales, could be } \\
\text { powerful drivers of future projects. }\end{array}$ & $\begin{array}{l}\text { Should a building last for } \\
\text { 200 years? How do we } \\
\text { measure our self-interest } \\
\text { as architects against the } \\
\text { need to protect and heal } \\
\text { the environment? A } \\
\text { binary is meant to be } \\
\text { questioned - how can we } \\
\text { evaluate our projects with } \\
\text { a plurality of criteria? }\end{array}$ \\
\hline $\begin{array}{l}\text { Student } \\
10\end{array}$ & $\begin{array}{l}\text { What role does } \\
\text { human agency have } \\
\text { to play in the role of } \\
\text { actively designed } \\
\text { systems? }\end{array}$ & $\begin{array}{l}\text { Much of my takeaway from the conversation } \\
\text { was seeing how the combination of our ideas } \\
\text { could create a conversation in which no one } \\
\text { person generated. Going forward I think it } \\
\text { would be good to understand the topics of } \\
\text { discussion that may emerge next Friday and } \\
\text { craft a review schedule in which we may be able } \\
\text { to explore more deeply on these individual } \\
\text { concepts rather than jumping from topic to } \\
\text { topic. }\end{array}$ & $\begin{array}{l}\text { How do we create an } \\
\text { architecture that offers } \\
\text { post-occupancy flexibility } \\
\text { for adaptive functionality? } \\
\text { What role does human } \\
\text { agency have to play in the } \\
\text { role of actively designed } \\
\text { systems? }\end{array}$ \\
\hline
\end{tabular}

\subsection{PROPOSED EXPANSION OF LOONEN'S TAXONOMY}

Loonen's taxonomy includes includes thermal, optical, airflow, and electrical responses in the adaptive skin. The students realized that the various works in the studio needed more defining terminology, and consequently they proposed an expansion of Loonen's taxonomy. Specifically, their concern was the timescale frequency of dynamic, adaptive, and active skin transformations. The frequency of transformations 
ranged from the continuous in response to temperature shifts to seasonal in response to larger changes in temperature, humidity and daylight hours. To this they added the question of agency (i. e., what provides the power for dynamic skin transformations). Three broad categories emerged through the student work. First, active skins may be powered by an energy source (fossil-fueled or renewable). Second, the skin's material may respond to changing temperature conditions by predictable movements, such as the laminated metal skins investigated by Sung $(2009,2016)$ and the bio-laminates investigated by Braaksma, Srivastava, \& Ulven (2018). Third, skin transformations may be human-powered and controlled by manual manipulations, e. g. an insulated panel layer that can be manually added to the building envelope, but that is used as site furniture in warmer months when the building is not cooled. A three-person group of students led a discussion of the potential for seasonal human-powered transformations of this kind to affect the potential for green economy jobs, even as they make buildings highly efficient.
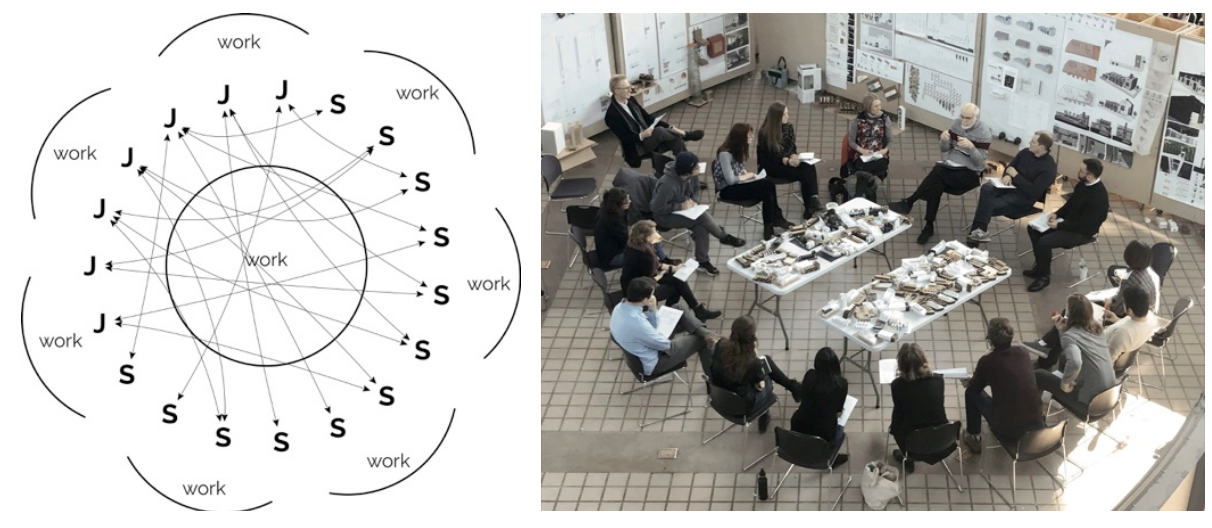

Figure 9: Discussion-based arrangement of the final review (Photo by Mike Christenson).

\subsection{CONCLUSIONS}

The Shifting Allegiances approach was necessary to engage complex topics such as being in a cyclical design and evidence loop, learning skills for energy modeling, interpreting results through design iterations, and producing net-positive results for an existing building - all in a short 7-week timeline. The cooperative structures created in the studio accelerated the learning process in several ways, not only because of student successes, but also through their failures. Comparisons in energy modeling for EUI results due to in-depth knowledge of, and participation in, their colleagues' work became second nature to the students. Anomalies in results became more apparent since all the students were working on the same existing building. Within a 7-week period the existing building was modeled several times, compared, and the impact of the variables and inputs was thoroughly understood. In addition, due to the ability to compare combinations of net-positive design strategies and multiple iterations, students were able to identify key variables that made small or substantive differences to performance results. Based on these variables, they were able to comparatively place all their projects on a three-dimensional chart that described the variety of design concepts studies by the group (Figure 8). This actively occurred spontaneously in a trial run of a student-led, discussion-based review model. Most importantly, due to this in-depth knowledge of the work, they were able to design the questions and lead the review discussions of the work in a way that was educational and relevant to them, further enhancing the learning due to ownership and leadership in various works. The collective exercise to arrange the projects by their defining variables also prompted them to realize that the variables provided by Loonen's taxonomy were insufficient to describe the studio's work. They further deepened their understanding by proposing expansions of the taxonomy that discussed the energy source for the dynamic skins.

In the end, the cooperative and comparative structures and the peer-learning and teaching that permeated the studio led to a deeper understanding of passive and responsive transformations of an existing building, leading in turn to net-positive performance. 


\section{REFERENCES}

Braaksma, Nick, Malini Srivastava, and Chad Ulven. 2018. "Exo-skins: Self-actuating, Thermallyresponsive, Laminated Bio-composites as Secondary Environments." In Facade Tectonics 2018 World Congress, Conference Proceedings (v. 1), Los Angeles, CA.

Elefante, Carl. 2018. "Existing Buildings: The Elephant in the Room.” Architect Magazine, Oct. 2018. https://www.architectmagazine.com/aia-architect/aiaperspective/existing-buildings-the-elephant-inthe-room 0 .

Lstiburek, Joseph W. 2007. “The Perfect Wall.” Ashrae Journal 49 (5): 74.

Loonen, R. C. G. M. 2010. Overview of 100 Climate Adaptive Building Shells. Eindhoven: Eindhoven University of Technology. https://pure.tue.nl/ws/portalfiles/portal/15945980/Loonen2010 OverviewOf10oClimateAdaptiveBui ldingShells.pdf.

Loonen, R. C. G., Marija Trčka, Daniel Cóstola, and J. L. M. Hensen. 2013. "Climate Adaptive Building Shells: State-Of-The-Art and Future Challenges.” Renewable and Sustainable Energy Reviews 25: 483-493. https://www.doi.org/10.1016/j.rser.2013.04.016.

Mang, Pamela, and Bill Reed. 2015. "The Nature of Positive." Building Research \& Information 43 (1): 710. https://doi.org/10.1080/09613218.2014.911565.

Sung, Doris Kim. 2009. “Skin Deep: Breathing Life Into the Layer Between Man and Nature.” In The American Institute of Architects Report on University Research, v. 3. Washington, D.C.: American Institute of Architects.

Sung, Doris. 2016. “A New Look at Building Facades as Infrastructure.” Engineering 2 (1): 63-68. https://doi.org/10.1016/J.ENG.2016.01.008

Srivastava, Malini, John Barton, Mike Christenson. 2019. “The Death of the Desk Crit." IN PRESS for the proceedings of, LESS TALK MORE ACTION, Stanford University (2019 Fall Conference of the Association of Collegiate Schools of Architecture).

Srivastava, Malini, \& Mike Christenson. 2018. "Play in Architectural Pedagogy: Shifting Allegiances and Trading Projects," IN PRESS for proceedings and presented at PLAY with the Rules (2018 Fall Conference of the Association of Collegiate Schools of Architecture). 